\title{
INCREASING THE EFFICIENCY OF PYROLYSIS
}

• .

E. R. Magaril, R. Z. Magaril, L. V. Trushkova

р льский федер льный университет, г. $к$ теринбург

юменский госуд рственный нефтег зовый университет, г.юмень

лючевые слов : пиролиз; селективность процесс ; выход этилен ;

иницииров ние процесс ; водород; этилен

Key words: pyrolysi; selectivity; ethylene output; initiation of the process; hydrogen; ethylene

ля производств этилен используется порядк 400 млн т/год углеводородного сырья - попутного нефтяного г $3 \quad 2^{-} 4$ И жидкого сырья, гл вным обр зом бензинов. ировое годовое производство этилен сост вляет порядк 140 млн т и прогнозируется его увеличение к 2020 г. до 200 млн т [1]. основе этилен производят зн чительную ч сть мировой нефтехимической продукции, и ее номенкл тур и объемы производств непрерывно р сширяются. сновным промышленным методом получения этилен является пиролиз нефтяных углеводородов. епрерывно р стущ я

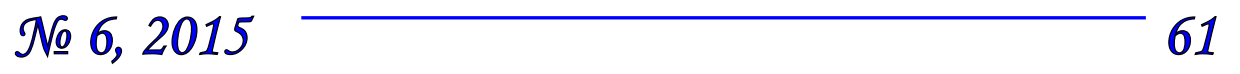


потребность в этилене обусловлив ет необходимость повышения эффективности методов пиролиз , позволяющих увеличить селективность по этилену.

иролиз протек ет в основном по р дик льно-цепному мех низму, и влиять н процесс принципи льно можно воздействием н ст дии продолжения цепи или н ст дию иницииров ния цепей. виду огр ниченности д нных по кинетике и мех низму ре кций р зличных углеводородов, т кже отсутствия системного изучения пиролиз сложных углеводородных смесей, эти методы в промышленном пиролизе не р зр бот ны, и весьм кту льной предст вляется з д ч их обоснов ния.

лияние водород н $\mathrm{cm}$ дию продолжения цепей. е кции продолжения цепей при пиролизе обусловлив ются в основном тремя ч стиц ми: томом водород · метильным 3 и этильным 25 р дик л ми. ост в первичных продуктов р сп д молекул углеводородного сырья з висит от строения обр зующихся в ходе цепного процесс $\mathrm{p}$ дик лов. сходя из обычного соотношения процентного выход мет н , водород и эт н 16:1,2:6 (м с. \%), с учетом молекулярных м сс,

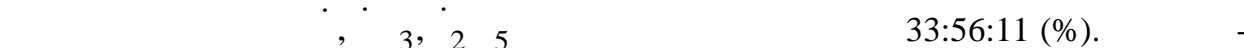
ку основное влияние н продолжение цепей обусловлено метильными р дик л ми и том ми водород, в н шем р ссмотрении роль этильных р дик лов не учитыв ется. ля определения р зличий в поведении метильных р дик лов и томов водород был исследов н относительн я ре кционн я способность связей - по отношению к ним.

целью определения относительной ре кционной способности связей - при ре кциях с томом водород втор ми н л бор торной моделирующей уст новке проведен пиролиз з д нной смеси индивиду льных углеводородов при сильном р зб влении водородом (сост в исходного сырья и продуктов определяли хром тогр фически). этих условиях метильный р дик л ре гирует с молекулой водород по ре кции (1)

$$
3^{+} \quad 2 \rightarrow 4^{+}
$$

со скоростью, зн чительно большей скорости ре кции углеводородов (2):

$$
3_{3}+\mathrm{R} \rightarrow \mathrm{CH}_{4}+\dot{\mathrm{R}}
$$

поскольку конст нт скорости ре кции (1) н порядок больше конст нты скорости ре кции (2). ким обр зом, ре кции з мещения по связям - идут только з счет томов водород по ре кции первого порядк по углеводороду (3)

$$
\dot{H}+\mathrm{RH} \rightarrow \mathrm{H}_{2}+\dot{R}
$$

н чения глубин р сп д $(y)$ индивиду льных углеводородов позволяют получить величины $k \tau$ :

$$
\lg (1-y)=k \tau
$$

где $k$ - конст нт скорости р сп д , $\tau$ - время (один ковое для всех углеводородов смеси). з соотношения глубин р сп д индивиду льных углеводородов вторы получили относительные ре кционные способности р зличных типов - связей. $\quad \mathrm{K}$, при пиролизе смеси, содерж щей бут н и проп н, с учетом количеств связей р зного тип соотношение конст нт скорости р сп д $\mathrm{p}$ вно:

$$
\frac{k_{C_{4} H_{10}}}{k_{C_{3} H_{8}}}=\frac{6 \cdot 1+4 x}{6 \cdot 1+2 x},
$$

где 3 единицу принят относительн я ре кционн я способность - связи в метильной группе, х - относительн я ре кционн я способность - связи в метиленовой группе. ким обр зом можно р ссчит ть относительную ре кционную способность - связи в метиленовой группе. н логично были получены относи- 
тельные ре кционные способности других типов - связей. олученные эксперимент льные результ ты приведены в т бл. 1 [2].

тносительн яре кционн я способность связей - при вз имодействии

с томом водород

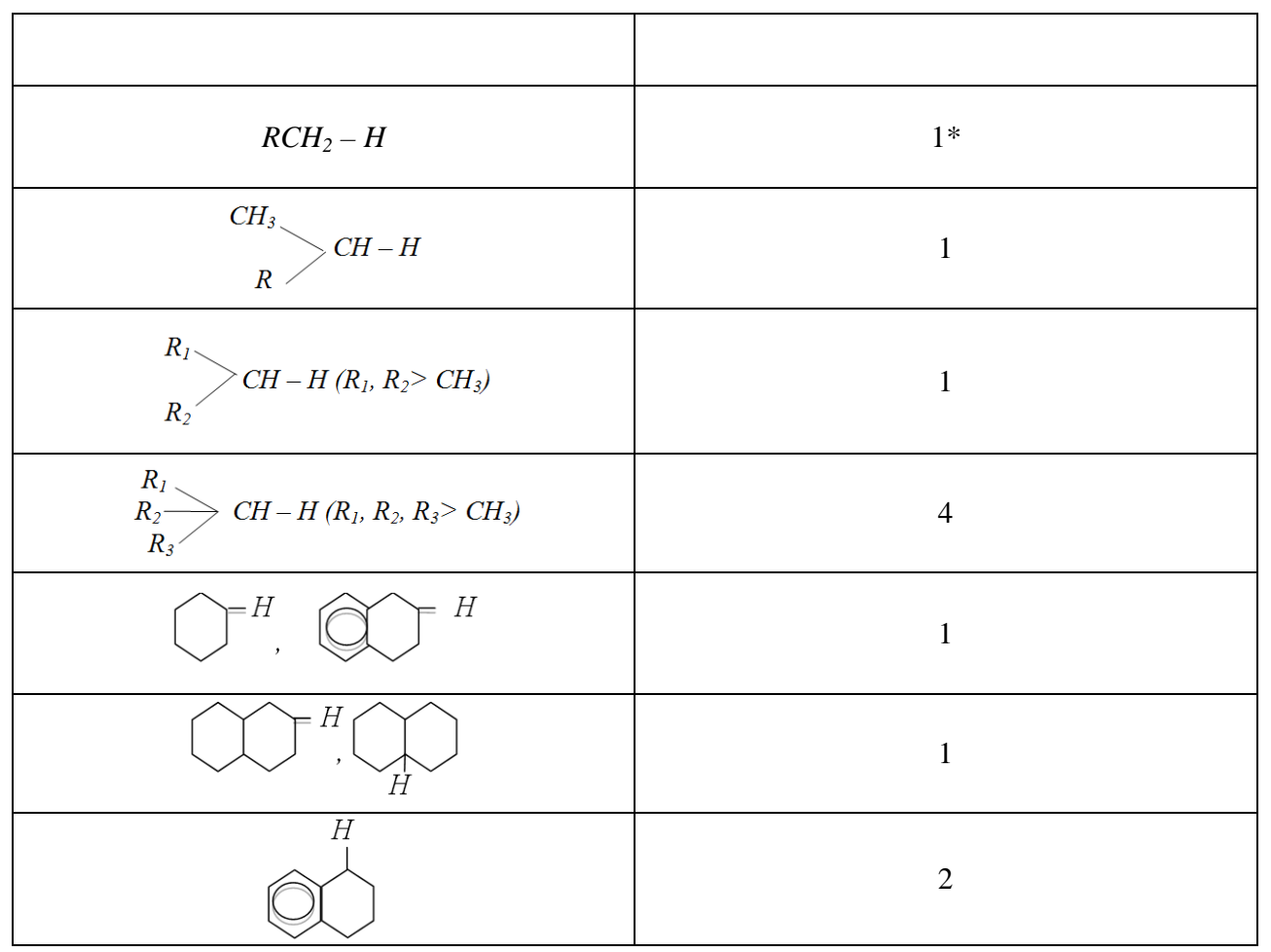

3 д нных т блицы следует, что томы водород один ково ре гируют с первичными и вторичными связями - , третичные связи в изо лк н х имеют относительную ре кционную способность, большую в 4 р 3 .

ля определения ре кционной способности связей - при ре кциях з мещения метильным р дик лом пиролиз проводился в токе гелия с доб влением 60 \% мол. пропилен . том водород ре гирует с пропиленом:

$$
\begin{gathered}
\dot{H}+C_{3} H_{6} \rightarrow n-\dot{C}_{3} H_{7} \rightarrow C_{2} H_{4}+\dot{C} H_{3} \\
\dot{H}+C_{3} H_{6} \rightarrow H_{2}+\dot{C}_{3} H_{5}
\end{gathered}
$$

результ те томы водород з мещ ются метильными и ллильными р дик л ми. К К к ре кции з мещения ллильных р дик лов 35 протек ют медленнее, чем метильных р дик лов 3 (величин энергии р зрыв связи $3^{-}$н 75 к ж/моль больше, чем для связи $35^{-}$[3]), ими можно пренебречь.

з полученных втор ми эксперимент льных результ тов т ким же обр зом, к к для томов водород , были оценены относительные ре кционные способности p зличных связей в ре кциях с метильным р дик лом, при принятии ре кционной способности первичной - связи, р вной единице. тносительные ре кционные 
способности - связей в ре кциях з мещения с метильными р дик л ми приведены в т бл. 2 [2].

р внение д нных т бл. 1 и 2 пок зыв ет, что томы водород пр ктически не селективны в ре кциях с первичными и вторичными связями, тогд к к метильные р дик лы весьм селективны. пример, в $н$-пент не с р вной вероятностью том ре гирует со всеми связями, и вероятность первичного р сп д с обр зов нием этилен , p вн я отношению числ первичных - связей к общему числу - связей в молекуле, сост вляет 6/12, то есть $50 \%$. ри ре кциях с $\boldsymbol{H}$-пент ном метильного р дик л с учетом неодин ковой ре кционной способности р зличных связей при вз имодействии с 3 вероятность обр зов ния первичных связей сост вит $\frac{6 \cdot 1}{6 \cdot 1+4 \cdot 4,5+2 \cdot 7}$, то есть $16 \%$. 3 ср внения этих результ тов очевидно, что проведение процесс пиролиз в условиях, когд метильные р дик лы 3 мещ ются том ми водород , зн чительно повыш ет селективность процесс по этилену.

тносительн яре кционн я способностьсвязей - при вз имодействии сметильным р дик лом

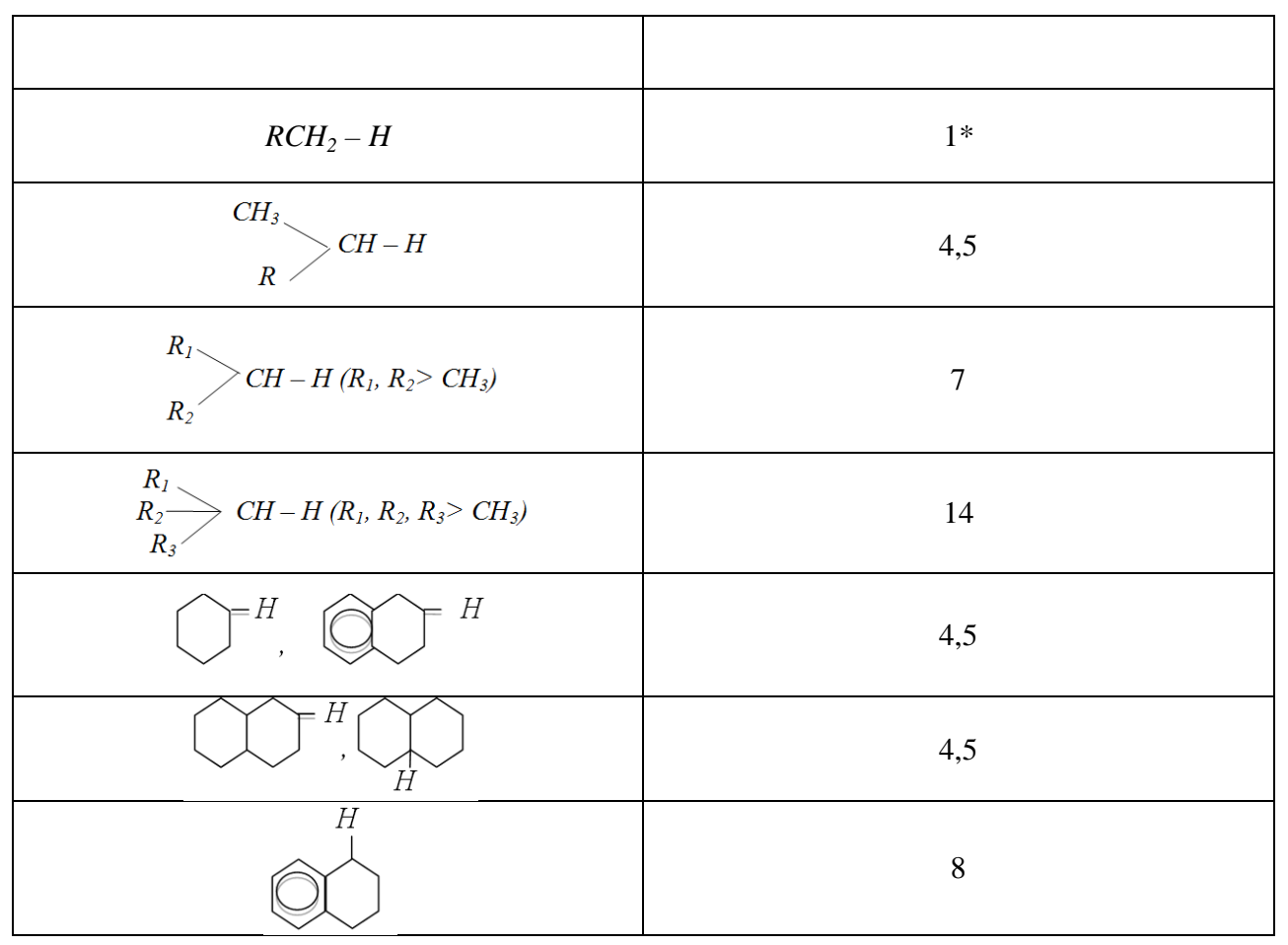

p боте [4] втор ми пок з но, что з мен метильных р дик лов н томы водород осуществляется при под че водород порядк $2 \%$ м с.н сырье. ри обр зов нии этилен в зн чительной концентр ции он р сходуется в результ те ре кции (8)

$$
\dot{R}+\mathrm{C}_{2} \mathrm{H}_{4} \longrightarrow \dot{C}_{2} \mathrm{H}_{3}+\mathrm{RH}
$$




$$
\dot{\mathrm{C}}_{2} \mathrm{H}_{3}+\mathrm{C}_{2} \mathrm{H}_{4} \longrightarrow \mathrm{C}_{4} \mathrm{H}_{7} \longrightarrow \mathrm{C}_{4} \mathrm{H}_{6}
$$

онст нт скорости ре кции винильного р дик л с водородом (9)

$$
{ }_{2}{ }_{3}+2 \longrightarrow \mathrm{C}_{2} \mathrm{H}_{4}+\dot{H}
$$

примерно н порядок больше конст нты скорости его ре кции с этиленом. ледов тельно, при обр зов нии $28 \%$ м с. этилен при содерж нии в смеси $2 \%$ м с. водород отношение их концентр ций сост вляет 1 моль: 1 моль, конденс ция этилен под вляется, и снижения его выход не происходит. лияние водород $\mathrm{H}$ результ ты пиролиз фр кции $85-150^{\circ}$ пок з но н рисунке.
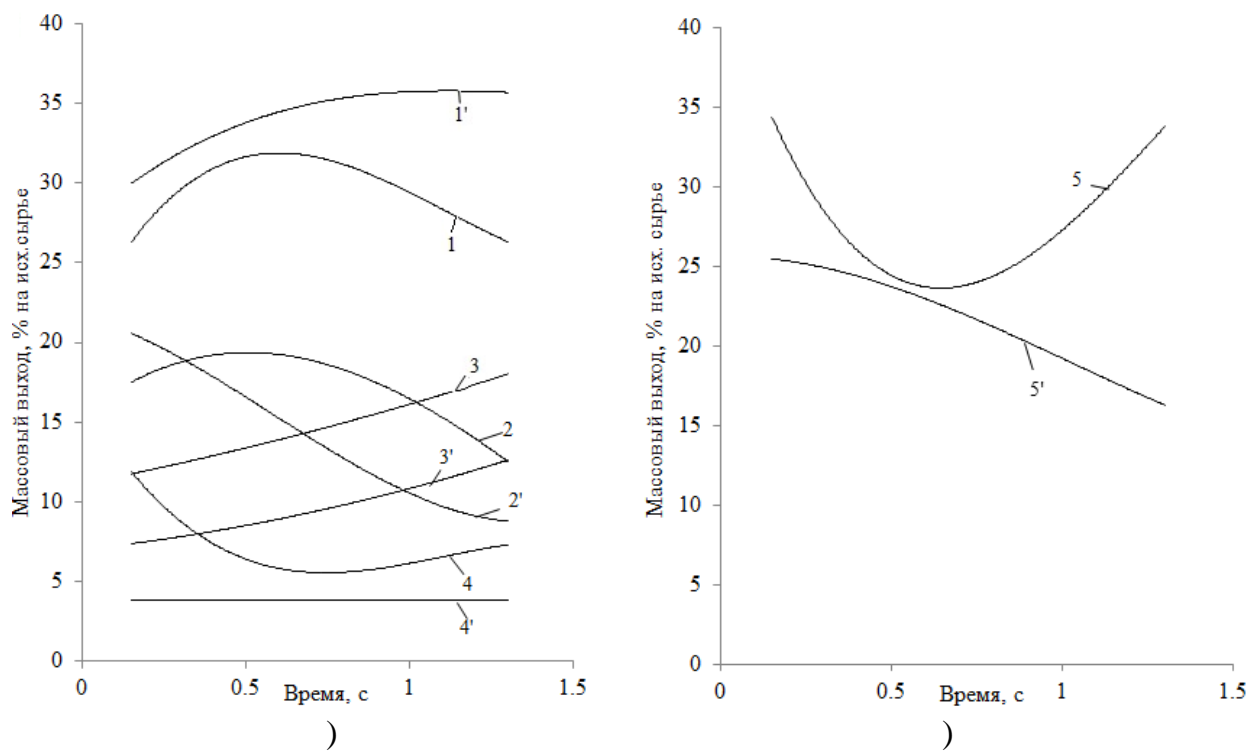

исунок. лияние водород н результ ты пиролиз фр кции $85-150^{\circ}\left(=810^{\circ}\right.$, общее д вление р вно тмосферному): ) г зообр зные продукты; б) жидкие продукты; 1 - этилен; 2 - пропилен; 3 -мет н; 4 - бут диен; 5 -жидкие продукты 5+, без водород ; 11-51-те же продукты при введении 2 \%м сс. водород

мен метильных $\mathrm{p}$ дик лов н томы водород приводит т кже к некоторому ускорению процесс , т к к к ре кция (1) быстрее ре кции (2), ре кция (3) зн чительно быстрее ре кции (2). ысокие п рци льные д вления водород в пиролизуемой смеси сниж ют выделение пироуглерод н стенк х ре кционного змеевик [5].

лияние ллен н ст дию иницииров ния цепей. корость ст цион рной цепной ре кции $W$ описыв ется ур внением (11)

$$
W=k_{1} \cdot[\dot{R}] \cdot[M],
$$

где $k_{1}$ - конст нт скорости продолжения цепей, $\dot{R}-$ ведущие цепь р дик лы, - молекулы сырья.

т цион рн я концентр ция ведущих цепь р дик лов определяется из р венств скоростей иницииров ния и обрыв цепей

$$
v=k_{2} \cdot[\dot{R}]^{2},
$$

где $v$ - скорость иницииров ния цепей, $k_{2}-$ конст нт скорости рекомбин ции р дик лов. 
ледов тельно,

$$
W=k_{1} \cdot \sqrt{\frac{\nu}{k_{2}}} \cdot[M]
$$

скорость цепной ре кции пропорцион льн скорости иницииров ния в степени 0,5.

Н ч льных ст диях пиролиз лк нов иницииров ние цепей происходит при р 3рыве связей - . же при м лой глубине $\mathrm{p}$ зложения обр зуются олефины, содерж щие связь - , осл бленную сопряжением с двойной связью примерно н 55 к ж [3].

втор ми было уст новлено, что термическое р зложение углеводородов сильно ускоряется лленом (проп диеном) (т бл. 3).

лияние ллен н глубину термического р сп д углеводородов

\begin{tabular}{|c|c|c|c|}
\hline \multirow{2}{*}{$\begin{array}{c}\text { об влен ллен, \% } \\
\text { мол. н углеводород }\end{array}$} & \multicolumn{2}{|c|}{ словия ре кции } & \multirow{2}{*}{$\begin{array}{c}\text { лубин р зложения } \\
\text { углеводород , \% }\end{array}$} \\
\hline & емпер тур , & ремя, с & \\
\hline 1 & 2 & 3 & 4 \\
\hline \multicolumn{4}{|c|}{ н-гексен-1 } \\
\hline 0 & 823 & 2,00 & 6,5 \\
\hline 0,5 & 823 & 2,00 & 20,1 \\
\hline 0 & 923 & 0,10 & 11,0 \\
\hline 0,5 & 923 & 0,10 & 21,4 \\
\hline \multicolumn{4}{|c|}{ н-гекс н } \\
\hline 0 & 923 & 0,06 & 5,2 \\
\hline 0,5 & 923 & 0,06 & 56,2 \\
\hline 0 & 963 & 0,02 & 4,5 \\
\hline 0,5 & 963 & 0,02 & 46,5 \\
\hline \multicolumn{4}{|c|}{ циклогекс н } \\
\hline 0 & 933 & 3,90 & 20,5 \\
\hline 0,5 & 893 & 0,55 & 20,5 \\
\hline 0 & 973 & 0,19 & 7,0 \\
\hline 0,5 & 973 & 0,19 & 53,5 \\
\hline \multicolumn{4}{|c|}{ тетр лин } \\
\hline 0 & 903 & 0,38 & 9,0 \\
\hline 1,5 & 903 & 0,38 & 45,0 \\
\hline 0 & 953 & 0,09 & 9,5 \\
\hline 1,5 & 953 & 0,09 & 55,6 \\
\hline \multicolumn{4}{|c|}{ дек лин } \\
\hline 0 & 923 & 0,26 & 20,5 \\
\hline 1,5 & 898 & 0,16 & 20,5 \\
\hline 0 & 973 & 0,04 & 2,3 \\
\hline 1,5 & 973 & 0,04 & 30,0 \\
\hline
\end{tabular}

лияние ллен н глубину ре кции термического р сп д углеводородов обусловлено снижением энергии ктив ции при доб влении ллен . езульт ты определения энергии ктив ции приведены в т бл. 4.

ценк конст нты скорости ре кции (14)

$$
{ }_{3} \mathrm{H}_{4}+{ }_{3}{ }_{8} \rightarrow \dot{C}_{3} H_{5}+{ }_{3}{ }_{7}
$$

д л величину порядк $10^{-11} \cdot e^{-\frac{181780}{R T}} \frac{c^{3}}{\text { молекул } \cdot c}$, для ре кщии. 
нергия ктив иии термического р сп д углеводородов в чистом виде и в присутствии ллен

\begin{tabular}{|c|c|c|c|}
\hline глеводород & $\begin{array}{c}\text { нергия ктив ции в } \\
\text { чистом виде, } \\
\text { к ж/моль }\end{array}$ & $\begin{array}{c}\text { об влено } \\
\text { ллен \% мол. } \\
\text { н углеводород }\end{array}$ & $\begin{array}{c}\text { нергия ктив ции с } \\
\text { доб вкой ллен }, \\
\text { ж/моль }\end{array}$ \\
\hline н-гексен-1 & $244 \pm 7$ & 0.5 & $163 \pm 7$ \\
\hline н-гекс н & $258 \pm 10$ & 0.5 & $154 \pm 13$ \\
\hline циклогекс н & $224 \pm 6$ & 0.5 & $130 \pm 10$ \\
\hline тетр лин & $215 \pm 16.5$ & 1.5 & $93 \pm 9$ \\
\hline дек лин & $151 \pm 10$ & 1.5 & $92 \pm 8$ \\
\hline
\end{tabular}

$$
{ }_{3} \mathrm{H}_{4}+{ }_{3}{ }_{6} \rightarrow 2 \dot{C}_{3} H_{5}
$$

конст нт скорости сост вил $10^{-11} \cdot e^{-\frac{113000}{R T}} \frac{c^{3}}{\text { молекул } \cdot c}[6]$.

т бл. 5 приведено ср внение скорости иницииров ния без ллен по ре кции мономолекулярного р зложения проп н (16)

$$
\mathrm{C}_{3} \mathrm{H}_{8} \rightarrow \dot{\mathrm{C}}_{2} \mathrm{H}_{5}+\dot{\mathrm{C}} \mathrm{H}_{3}
$$

и с доб влением 1 мол. \% ллен по ре кциям (14) и (15).

з приведенных результ тов р счет видно, что ллен ускоряет ст дию иницииров ния при темпер туре ниже 1000 .

ри пиролизе ллен обр зуется при темпер тур х выше 1000 в результ те весьм эндотермичного р сп д по ре кции (17)

$$
35 \rightarrow 34^{+}
$$

и не влияет при этих темпер тур х н скорость иницииров ния. ри ректифик ции продуктов ллен выделяется в сост ве проп новой фр кции, и рециркуляция ее в сырье повыш ет скорость пиролиз при невысоких темпер тур х, увеличив я выход этилен .

ценк изменения скорости иницииров ния термического р сп д углеводородов при доб влении ллен

\begin{tabular}{c|c|c|c|c|c|c|}
\hline \multirow{2}{*}{,} & \multicolumn{2}{|c|}{ корости ре кций, молекул см $^{-3}$ сек $^{-1}$} & \multicolumn{3}{c|}{ тносительные скорости } \\
\cline { 2 - 7 } & $\begin{array}{c}\text { ре кция } \\
(16)\end{array}$ & $\begin{array}{c}\text { ре кция } \\
(14)\end{array}$ & $\begin{array}{c}\text { ре кция } \\
(15)\end{array}$ & $\begin{array}{c}\text { ре кция } \\
(16)\end{array}$ & $\begin{array}{c}\text { ре кция } \\
(14)\end{array}$ & $\begin{array}{c}\text { ре кция } \\
(15)\end{array}$ \\
\hline 833 & $10^{11 . / / 5}$ & $10^{13.58 /}$ & $10^{14.906}$ & $1 *$ & 65 & 1350 \\
\hline 900 & $10^{15.459}$ & $10^{14.452}$ & $10^{15.445}$ & $1 *$ & 10 & 95 \\
\hline 1000 & $10^{15.479}$ & $10^{15.489}$ & $10^{16.088}$ & $1^{*}$ & 1,0 & 1,2 \\
\hline 1053 & $10^{16.405}$ & $10^{15.965}$ & $10^{16.384}$ & $1^{*}$ & 0,4 & 1,0 \\
\hline
\end{tabular}

ри этом обр зов ние тяжелых продуктов конденс ции уменьш ется, т к к к их обр зов ние идет по молекулярному мех низму. т бл. 6 приведены д нные по влиянию ллен н выход этилен и обр зов ние продуктов конденс ции при пиролизе. т бл. 7 приведены выходы основных продуктов пиролиз н-гекс н при $800^{\circ}$. олученные д нные пок зыв ют, что темпер тур пиролиз при 3 д нном его времени может быть снижен применением ллен .

ыл проведен промышленный пробег н пиролизной уст новке м лой мощности (60 тыс. т этилен в год). робег проводился в неоптим льном режиме. место водород использов л сь мет но-водородн я фр кция с концентр цией водород $80 \%$ мол. с доб вкой ллен $0,5 \%$ м с. н сырье. присутствии ллен выход этилен повысился н 21,2\% отн. 
лияние ллен н результ ты пиролиз фр кции 70-100 ${ }^{\circ}$ бензин -р фин т при $820^{\circ}, 0.1 \mathrm{M}$, времени пиролиз 1 , отношение объемов сырья и инертного р зб вителя (гелий) р вно 1:3,66 моль/моль

\begin{tabular}{|c|c|c|}
\hline \multirow{2}{*}{$\begin{array}{c}\text { об влен ллен, } \\
\% \text { м с. н сырье }\end{array}$} & \multicolumn{2}{|c|}{ ыходы, \% м с. н сырье } \\
\cline { 2 - 3 } & $\mathrm{C}_{2} \mathrm{H}_{4}$ & $\mathrm{C}_{5+}$ \\
\hline 0,0 & $24,7 \pm 0,7$ & $22,3 \pm 0,6$ \\
\hline 0,3 & $27,3 \pm 0,2$ & $19,1 \pm 0,6$ \\
\hline 0,5 & $27,8 \pm 0,3$ & $17,3 \pm 0,5$ \\
\hline
\end{tabular}

ыходы основных продуктов пиролиз н-гекс н при $800^{\circ}$, соотношение сырья к инертномур зб вителю (гелий) 1:3,66 моль/моль

\begin{tabular}{|c|c|c|r|r|}
\hline \multirow{2}{*}{$\begin{array}{c}\text { об влено ллен } \\
\% \text { м с. н сырье }\end{array}$} & ремя пиролиз, с & \multicolumn{3}{|c|}{ ыходы продуктов, \% м с. } \\
\cline { 3 - 5 } & & 24 & 3 & 4 \\
\hline 0 & 0,09 & 33,0 & 17,3 & 5,0 \\
\hline 0,3 & 35,5 & 18,4 & 6,5 \\
\hline
\end{tabular}

ким обр зом, теоретически обоснов ны методы совершенствов ния процесс пиролиз , повыш ющие селективность по этилену, использующие влияние водород н ст дию продолжения цепей и ллен н ст дию иницииров ния цепей. езульт ты проведенных втор ми исследов ний пок зыв ют, что эффективность пиролиз может быть зн чительно повышен в результ те под чи в сырье около 2 \% м с. рециркулирующего водород , выделяемого из г 3 пиролиз и рециркуляции проп новой фр кции, выделяемой из г з пиролиз , котор я содержит обр зующийся при пиролизе ллен.

писок литер туры

1. [ лектронный pecypc]. ежим доступ : http://media.corporate-ir.net/media_files/IROL/11/ 110877/05_Global_Ethylene_Market_Outlook_Eramo.pdf

2. орзун . . г рин . . тносительные ре кционные способности р зличных связей углеводородов // ефетехимия. - 1985. - . 25., - № 4. - . 514-523.

3. орзун . ., г рил . . . ермические процессы перер ботки нефти. - : . 2008. - .10-20.

4. Magaril E. \& Magaril R., Increasing the selectivity of the hydrocarbon feedstock pyrolysis. WIT Transactions on Ecology and the Environment, Vol.186,WIT Press, UK, pp. 529-534, 2014.

5. г рил . . еоретические основы химических процессов перер ботки нефти. - : , 2010. - C. 69

6. Klementyev A., Magaril R., Korzun N. \&Magaril E. Efficiency improvement of pyrolysis. WIT Transactions on Ecology and the Environment, Vol.190 (2), WIT Press, UK, pp. 861-865, 2014.

ведения об втор $x$

г рил лен оменовн, д. т. н., профессор, $з$ ведующий к федрой « кономик природопользов ния», р льский федер льный университет имени первого резидент оссии

льцин , г. к теринбург, тел. 8(343)37433200, e-mail:magaril67@mail.ru

г рил омен еликович, д. т. н., профес сор, гл вный н учный сотрудник к федры "ерер ботк нефти и г з », юменский госуд рственный нефтег зовый университет, г. юмень, meл.8(3452)256925, e-mail: png@tsogy.ru

рушков юбовь сильевн, к. х. н., доиент, юменский госуд рственный нефтег зовый университет, тел. 8(9044)906251, e-mail: Trushkova53@mail.ru
Information about the authors

Magaril E. R., professor, Doctor of Engineering, head of the chair "Environmental economics», the Ural Federal University named after Boris Yeltsin, first President of Russia, Yekaterinburg, phone: 8(343)37433200, e-mail: magaril67@mail.ru

Magaril R. Z., Doctor of Engineering, professor, senior research worker of the chair "Oil and gas processing», Tyumen State Oil and Gas University, Tyumen, phone: 8(3452)256925, e-mail: png@tsogy.ru

Trushkova L. V. Candidate of Science in Chemistry, Tyumen State Oil and Gas University, phone: 8(9044)906251,e-mail: Trushkova53@mail.ru 